\title{
What about the wait times Canada isn't tracking?
}

Cite as: CMAJ 2020 September 14;192:E1081-2. doi: 10.1503/cmaj.1095896

Posted on cmajnews.com on August 28, 2020

\section{Part two of Waiting for Change, a special series on access to care.}

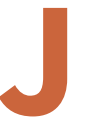

anet Lunn was on a wait list for four years to see a neurologist in Halifax for pain that felt like "an immense amount of pressure" on her temple and behind her eye. The pain would wake her up in the night, often only allowing her a few hours of sleep.

"I started developing anxiety about going to sleep because I knew the pain would hit," Lunn says. While she waited for specialist care, she lost her job, and her long-term relationship ended - both events she attributes partly to her lack of sleep.

When Lunn finally saw the neurologist, he diagnosed her with cluster headaches, prescribed her medication and readjusted another one she'd been taking. The consult took 45 minutes.

Now, Lunn is sleeping better and only gets cluster headaches once in a while. "Things are where l'd like them to be now, but the waiting period was one of the hardest times of my life," she says.

Long delays like Lunn experienced are a familiar story in Canadian health care, contributing to worse medical outcomes and serious economic and psychological costs. But across the country, efforts to monitor wait times are patchy and focus mostly on surgical and diagnostic services. Meanwhile, the question of tracking nonsurgical waits, like the wait to see a neurologist, divides experts.

\section{Which wait times are monitored across Canada?}

The Canadian Institute for Health Information tracks waits for "priority procedures" as defined in 2004 by former prime minister

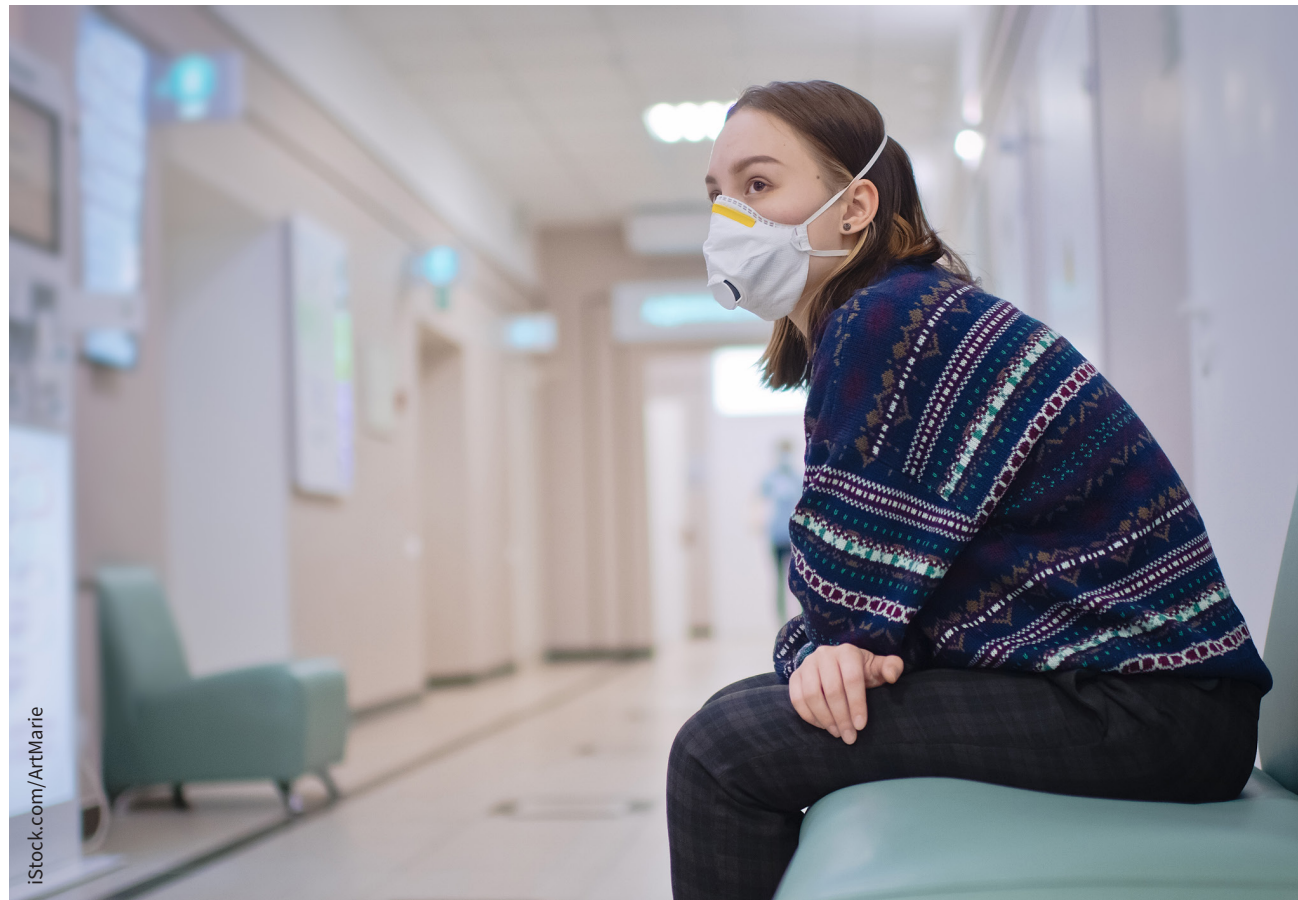

Patients can wait years for access to nonsurgical health services, yet there's little accountability for those delays.

Paul Martin and provincial and territorial premiers. These include wait times for hip and knee replacements, hip fracture repair, cataract surgery, cardiac bypass surgery, radiation therapy, computed tomography and magnetic resonance imaging scans, and some cancer surgeries.

It's unclear why the premiers deemed these a higher priority than others, but ease of measurement likely played a role, says Dr. Chris Simpson, who chaired the Wait Time Alliance, which set national benchmarks and reported on progress to reduce wait times.

Some provinces track other wait times as well. Ontario, for example, publicly reports additional surgical, diagnostic and cancer care wait times, but doesn't track nonsurgical ones, such as waits to see a psychiatrist or rheumatologist. According to David Jensen of Ontario's Ministry of Health, the provincial government doesn't track nonsurgical wait times internally either. Similarly, British Columbia monitors all surgical wait times but doesn't track nonsurgical waits.

Nova Scotia tracks and publicly reports the widest range of wait times of any province, including average nonsurgical waits. For example, the government reports that $50 \%$ of patients see a neurologist within 98 days, while $90 \%$ see someone within 334 days. The provincial government also tracks wait times at a more granular 
level, monitoring how long patients wait according to their urgency, but those data aren't made public.

The information helps the government decide where to direct resources, says Dr. Christine Short, chief of medicine for Nova Scotia's central zone. "If a clinic is asking for human resources or equipment, wait times are important so that we have a baseline, and we can see what change happens as a result of that investment," Short says. "Transparency is the most important thing."

\section{What do we know about nonsurgical waits?}

Outside of Nova Scotia, the available data on nonsurgical, nondiagnostic wait times in Canada come from a handful of one-off studies. One study of 770 referrals in Ontario, published in 2017, found that patients waited longest to see specialists in endocrinology, gastroenterology, allergy medicine and neurology. More than one in 10 patients referred to see specialists in these fields were still waiting a year later. Another small study had similar findings.

A further source of data on nonsurgical wait times is ConsultLoop, an e-referral service that ran from 2016 to 2019 in Ontario. Founder Dr. Ilan Shahin published a report on about 12500 referrals made through the system to more than 2000 specialists in Ontario. The average wait time was 49 days, and the longest nonsurgical waits were in neurology, gastroenterology and respirology, with average delays of 98,84 and 74 days, respectively. Shahin says it's unfortunate that the health system doesn't track wait times more systematically. "What does it say about a system that spends billions a year, but doesn't have this basic information?"
Qualitative information about waits would also be useful in determining which ones are a problem. Dr. Veronica Legnini, a family physician in Kingston, says that delays in specialist care for seemingly benign conditions can have surprisingly high costs for the health system, as patients often rely on repeat visits to emergency departments or their family doctor to manage symptoms while they wait.

The toll on patients can be heavy, too, One of Legnini's patients lived with chronic diarrhea for a year while they waited to see a gastroenterologist. Another patient waited a year to see a respirologist for a chronic cough that affected their work and sleep. "It's just so messed up," Legnini says.

Likewise, in Nova Scotia, Short says that procedures deemed "semi-urgent" and "nonurgent" have proven the most difficult to deliver in timely ways. And the situation has only grown worse as the COVID-19 slowdown delayed many procedures for months. Nova Scotia has rebooked most of the surgeries cancelled in the spring due to the pandemic. But the province has yet to contend with thousands more that would have been booked during the lockdown period.

\section{Would tracking nonsurgical waits be useful?}

Tracking wait times gives doctors and patients a better sense of how long patients may wait for care and provides some public accountability, but some experts question whether wait times are the right metric to monitor.

Dr. John Neary, a general internist at St. Joseph's Healthcare Hamilton, says that the average wait time for a clinic, let alone a specialty, "is a metric that loses an awful lot of information." Average wait times for specialists don't capture the appropriateness of the referrals in question, for example, if a doctor refers a patient with an endocrinological problem to an internist rather than an endocrinologist to try to get them seen sooner.

Neary notes that specialists could lower their average wait times by rejecting referrals or treating "very easy problems extremely quickly." He argues it would be better to "create metrics that truly represent the access to care that we are fundamentally concerned with," such as measuring how long it takes patients with a specific condition to receive appropriate treatment, rather than focusing on access to a type of specialist.

Dr. Jason Sutherland of the Centre for Health Services and Policy Research at the University of British Columbia explains that surgical wait times were "the low-hanging fruit" to track because patients are automatically entered into a surgical wait time registry when their operating room time is booked.

Although tracking nonsurgical times would likely benefit the health system, it would also burden health providers with additional administrative work, potentially sparking a backlash, Sutherland says.

However, Legnini argues that providing more accurate, clinic-specific wait times, as opposed to an estimated average wait based on specialty, would reduce uncertainty and administrative burden in the long run. Doctors and patients could save time spent following up on appointments if they knew the actual wait to see a given specialist, Legnini says. "People don't realize the behind-the-scenes scrambling we do to try and get people seen in a decent amount of time."

Wendy Glauser, Toronto, Ont. 